\title{
LOS FONDOS ARTÍSTICOS Y DOCUMENTALES EN LOS MUSEOS ONLINE DE ARTE CONTEMPORÁNEO: INFORMACIÓN VERSUS CONTEXTUALIZACION
}

Data recepción: 2010/09/21

Data aceptación: 2011/09/19

Contacto autor: ndelrio1@telefonica.net
J. Nicolás del Río Castro

Universidade de Santiago de Compostela

\section{RESUMEN}

Los museos en Internet se han consolidado como recursos de ocio, aprendizaje y trabajo para un público global. A pesar de ello, un ámplio número de museos de arte contemporáneo tiende a presentar sus fondos online siguiendo modelos internos de catalogación y documentación, más que a través de estrategias de difusión para una audiencia amplia y diversificada. En consecuencia, los museos online de esta tipología suelen funcionar como repositorios digitales, cuando la información que proporcionan es amplia, o como folletos publicitarios del museo físico, cuando la información es menos abundante. Este artículo analiza los fondos artísticos y documentales de 40 museos online de arte contemporáneo y presenta alternativas de divulgación no basadas únicamente en la clasificación de datos sino en la contextualización de significados.

Palabras clave: museos online, webs de museos, museología virtual, arte contemporáneo, contextualización

\section{ABSTRACT}

Online museums have established themselves as leisure, learning and work resources for global audiences. However, a large number of contemporary art museums tend to communicate their online assets according to internal cataloguing and documentation models, rather than through communication strategies geared to a large and diverse audience. Consequently, this type of museums usually become digital repositories of data when information is vast, or brochures for the physical museum, when information is scarce. The present essay analyzes the artistic and documental online assets of 40 museums of contemporary art, and presents alternative communication models not based solely on data classification, but on meaning contextualization.

Keywords: online museums, museum websites, virtual museology, contemporary art, contextualisation

Los primeros museos en la Red surgieron a mediados de los años $90^{2}$. Después de más de quince años de asentamiento y consolidación, han quedado atrás las reticencias iniciales sobre su valor y función ${ }^{3}$. En la actualidad, la presen-
Cuando los museos eran gabinetes de curiosidades enfocados principalmente a la adquisición y el mantenimiento de las colecciones, cualquier objeto nuevo y desconocido era una fuente de asombro. La misión del museo en aquel momento — desde su punto de vista - era muéstranos el mundo. Ahora con la comunicación instantánea y el acceso ilimitado a imágenes e información, la misión ha cambiado a dinos qué significa. ${ }^{1}$

cia en Internet se entiende como un elemento de apoyo a la misión del museo y se aprecia su capacidad para ayudar a cumplir objetivos institucionales. A este respecto, el museo online, como complemento del museo físico ${ }^{4}$, busca un 
equilibrio entre mercado y cometido. Es decir, combina la promoción de su ubicación física entre visitantes locales y turistas con la producción de contenidos online destinados a una audiencia global y diversificada. Sin embargo, aunque la inmensa mayoría de museos presentes en la Red proporciona información sobre el acceso al edificio y las actividades que tienen lugar en él, pocas instituciones han desarrollado una verdadera oferta de contenidos online para los visitantes que se conectan con una finalidad diferente a la visita presencial.

La mayor parte de museos de arte contemporáneo -a juzgar por los analizados en este estudio- basa la difusión de sus fondos online en una presentación por categorías (artistas, departamentos, fechas, etc.) cuyo contenido consiste en imágenes de reducido tamaño acompañadas de escuetas fichas técnicas. Sólo en ocasiones puntuales, algunos museos añaden breves textos introductorios o información adjunta para descargar. Este planteamiento resulta muy próximo a modelos internos de catalogación y documentación que resultan especialmente relevantes para públicos expertos pero poco significativos para visitantes no expertos. Ya en 1999 Teather y Wilhelm proponían distinguir entre museos online enfocados hacia los objetos y la información y museos online concebidos para la gente y el significado ${ }^{5}$. Aplicando esta distinción a los museos actuales de arte contemporáneo en la Red, la primera categoría refleja el patrón más extendido entre los museos estudiados, mientras que la segunda apenas se contempla y permanece aún como un objetivo deseable.

Este artículo analiza cómo 40 museos de arte contemporáneo de todo el mundo presentan sus contenidos en Internet con una finalidad adicional a la promoción de visitas al museo físico. Por ello, en el estudio se ha ignorado la información de tipo general destinada a facilitar la visita al edificio y se ha investigado únicamente la oferta de fondos artísticos y documentales. No obstante, para realizar una valoración adecuada de éstos es preciso tener en cuenta que los museos en la Red presentan, con respecto a los museos físicos, características particulares que condicionan la organización y el acceso a los recursos online. Dos son los aspec- tos principales a considerar: el propio medio online, que redefine el concepto de museo, y los contenidos online, cuyo principio organizativo es relacional e invita a una consulta abierta y flexible de la información ${ }^{6}$.

\section{El medio online}

Un museo en la Red contiene reproducciones digitales de obras artísticas. Esta particularidad hace que se pierdan características esenciales asociadas al objeto físico como el tamaño, el volumen o la textura, al igual que sus parámetros de autenticidad y originalidad. El museo online desdibuja aspectos que han sido tradicionalmente utilizados como base organizativa de la cultura museística, ya que difumina las fronteras entre la información primaria (el objeto artístico), la secundaria (datos sobre el objeto) y terciaria (interpretación del objeto) ${ }^{7}$. Esta particularidad contribuye a que la obra artística se desmaterialice y que su lugar lo ocupe la información, que se convierte en "el nuevo material constructivo de los museos en la Red"8.

La desmaterialización no afecta sólo al objeto artístico sino también al espacio museográfico ya que en el medio online los museos son entornos desprovistos de limitaciones arquitectónicas. La ausencia de referencias físicas hace que la presentación de los objetos artísticos sea mucho más flexible y no tenga por que respetar ni imitar necesariamente los patrones de la museografía tradicional.

\section{Los contenidos online}

En el museo físico, si el visitante quiere obtener más información de la que ofrecen paneles, cartelas, folletos o audioguías, puede apuntarse a una visita guiada, visitar el centro de documentación o adquirir una publicación en la tienda. En Internet la limitación de acceso a información adicional no existe —al menos en teoría- porque "todo enlaza con todo". La conectividad $^{10}$ que ofrece la Red permite relacionar datos en una cadena prácticamente infinita. Esto resulta especialmente relevante para los museos ya que, como señala el ICOM, el soporte digital permite "capturar y preservar la información polifacética presente en los objetos" ${ }^{\prime 11}$. Es decir, facilita la presentación de las 


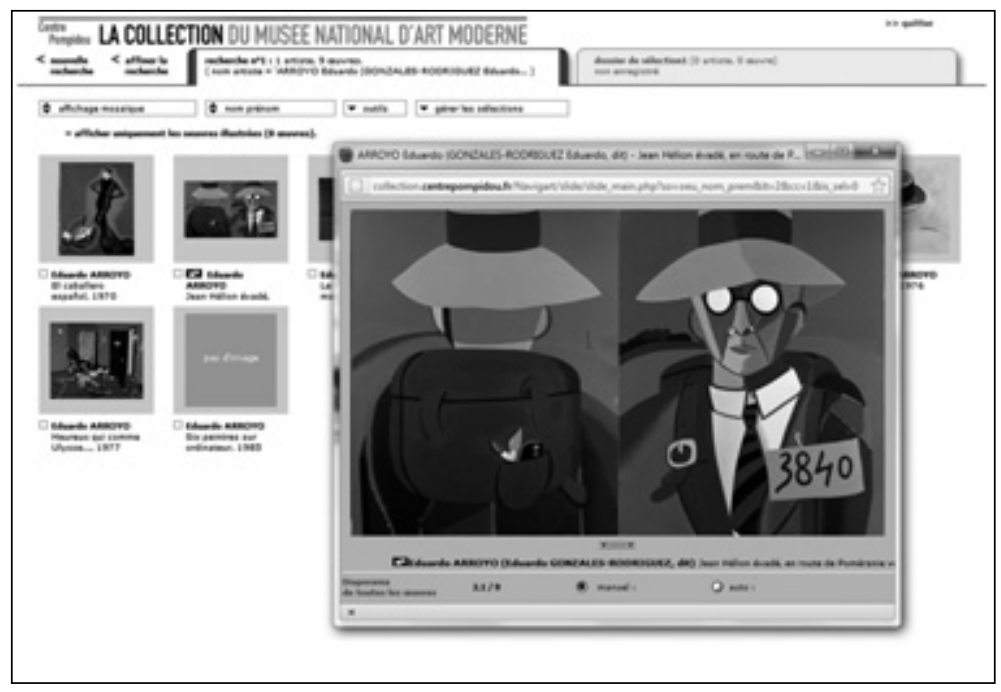

Fig. 1. Colección online del Centro Pompidou. Base de datos.

capas superpuestas de información que contiene cada obra: aspecto físico, valor artístico, datos técnicos, procedencia, interpretación, etc.

Adicionalmente, la capacidad de interrelación de la Red favorece un acceso autodirigido a la información ya que los datos asociados mediante vínculos facilitan una visita selectiva, marcada por la consulta de aquellos contenidos que despiertan un interés personal. De este modo, la experiencia online no se reduce a una actividad meramente contemplativa sino que cada visitante tiene la opción de construir sus propios objetos de información ${ }^{12}$ y dejar de ser un sujeto-espectador para convertirse en un sujeto-usuario ${ }^{13}$.

Los dos factores citados convierten la Red en un medio versátil para difundir los fondos de cualquier museo de una forma extensa, relacional y significativa. A pesar de ello, la difusión de fondos artísticos y documentales que proponen los museos aquí analizados en pocas ocasiones da muestras de aprovechar ese potencial.

\section{La difusión online de fondos artísticos}

La presentación de los fondos museográficos en la Red se realiza principalmente mediante tres formatos: colecciones, exposiciones y módulos interactivos. Las colecciones online proponen, con ligeras variantes, un acercamiento a las obras similar a la presentación en las salas. En el museo físico el grupo de piezas que comparte el mismo espacio expositivo es el resultado de una selección previa que las presenta como un conjunto relacional; adicionalmente, cada obra cuenta con una cartela que, de forma sucinta, aporta datos específicos de cada pieza. En la Red el resultado es similar cuando la colección se presenta a través de bases de datos e índices. Así ocurre, por ejemplo, en la web del Centro Pompidou, que cuenta con más de 60.000 registros online procedentes de su programa de gestión y catalogación NavigArt ${ }^{14}$. El resultado de una búsqueda (la Fig. 1 muestra una consulta sobre Eduardo Arroyo) proporciona únicamente una serie de imágenes y sus fichas técnicas. En este caso, el conjunto de obras mostradas no es el resultado de un planteamiento específico de divulgación museográfica sino del interés particular de un visitante que momentáneamente se convierte en comisario al seleccionar un conjunto de fondos que resultan de su interés. A pesar de la flexibilidad de un sistema que ofrece hasta diez criterios de búsqueda (título, artista, país, fecha, etc.) su funcionalidad se reduce a acotar la base de datos online al rango de resultados 


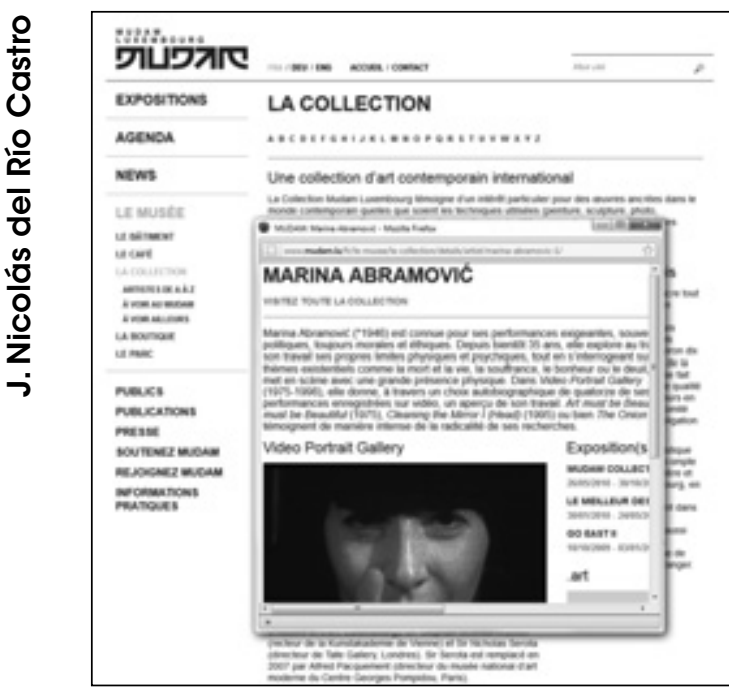

Fig. 2. Colección online del MUDAM de Luxemburgo. Índice de artistas.

solicitados por el usuario. La apreciación de las obras, por tanto, no depende de una propuesta desarrollada por el museo, sino de los conocimientos previos de cada visitante. Otros museos que ofertan sus fondos a través de bases de datos con una funcionalidad similar, aunque de menor envergadura, son el IMMA de Dublín, el ARTIUM de Victoria-Gasteiz o el Hirshhorn de Washington.

La presentación mediante índices o directorios produce idénticos resultados a los que proporcionan las bases de datos. El MUDAM de Luxemburgo, el ICA de Boston o el Kunstmuseum de Wolfsburg son algunos de los museos que ofrecen índices alfabéticos de artistas como único criterio articulador de la colección online. Otros museos, como el Whitney de Nueva York, amplían esta opción y utilizan dos índices separados (artistas y décadas) para proporcionar mayor flexibilidad de búsqueda a los visitantes. Aún así, este tipo de acceso resulta especialmente limitado y su consulta produce resultados poco significativos para los públicos menos especializados.

El acceso a la colección mediante bases de datos o índices parece indicar que aquellos mu-

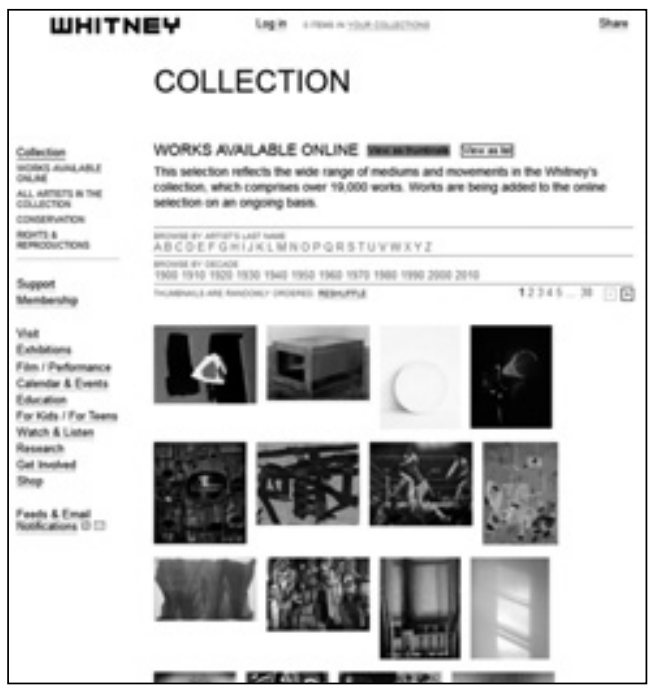

Fig. 3. Colección online del museo Whitney. Índices (artistas y décadas) y una selección de imágenes.

seos que optan por esta solución conciben sus fondos en la Red como un servicio a investigadores o profesionales interesados en localizar información de carácter técnico. La ausencia de recursos interpretativos relativiza el valor de la consulta para un amplio segmento de público ya que la información que ofrece el museo no ayuda a la apreciación de la obra ni aporta referencias adicionales que sirvan de punto de partida para profundizar en ella. Por una parte, los resultados de la consulta requieren cierto nivel de conocimiento sobre arte contemporáneo -es necesario saber qué buscar-y, por otra, el acceso a los fondos exige estar familiarizado con las taxonomías que el museo emplea para gestionar sus fondos. Algunas instituciones han tratado de solventar estas carencias añadiendo desde los índices de artistas breves reseñas sobre cada creador, como el MUDAM de Luxemburgo (Fig. 2), o complementando los índices con una selección de imágenes, como el Whitney de Nueva York (Fig. 3). En el primer caso la información ofrece una aproximación básica al discurso de cada artista y ayuda a situar su producción en un contexto general. En el segundo caso, la selec- 


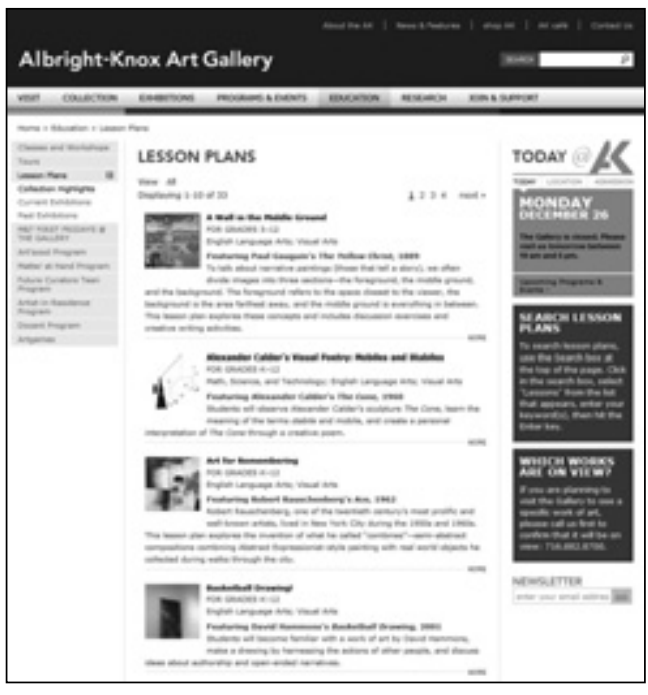

Fig. 4. Colección del Albright Knox de Búfalo. Una selección de obras con textos para docentes.

ción de imágenes ofrece la opción de una consulta visual que ya no requiere necesariamente conocimientos sobre arte.

Un segundo grupo de museos ha optado por alejarse de modelos basados en catálogos extensos y ha decidido dedicar su atención a una selección reducida de piezas. En este caso, cada obra está acompañada, además de su ficha técnica, de un texto introductorio que contribuye mínimamente a su interpretación. Así, el Albright-Knox de Búfalo ofrece 52 obras, a las que añade materiales educativos para centros académicos de primaria y secundaria (Fig. 4) y el MART de Trento acompaña 204 obras con textos específicos sobre cada pieza y su creador a los que, puntualmente, añade un fichero de audio sobre algún aspecto relacionado. Una variante de este tipo de contextualización consiste en utilizar un texto de presentación genérico para las obras englobadas dentro de un mismo movimiento artístico o momento temporal. De este modo, la contextualización deja de ser individual y hace referencia al grupo aunque la presentación de cada obra revierte al modelo básico de imagen y ficha. El Patio Herreriano, por ejemplo, sigue esta pauta y presenta su

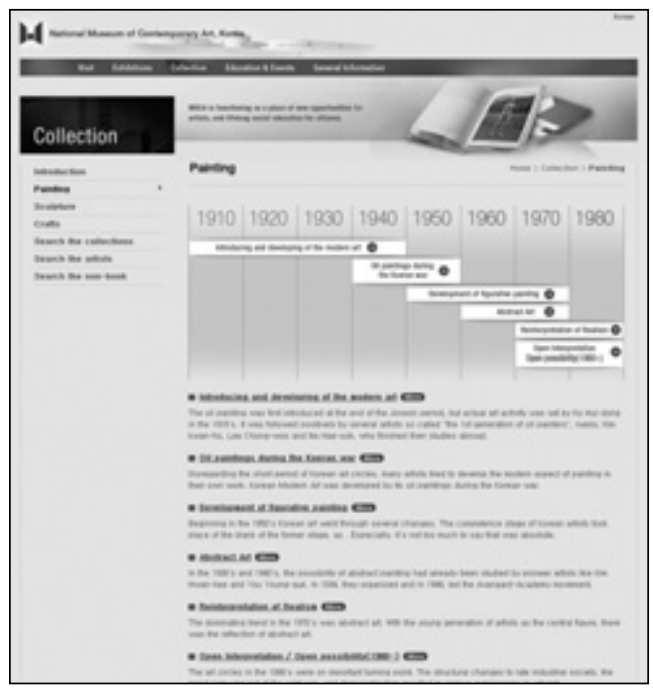

Fig. 5. Colección online del MOCA de Seúl, Corea. Fondos de pintura a partir de una cronología.

colección en bloques precedidos de una introducción en texto. El Reina Sofía distribuye su colección en la Red a partir de un plano de las salas (organizadas cronológicamente), haciendo que coincidan la presentación física y online. Por su parte, el MOCA de Seúl presenta como elemento introductorio un gráfico de periodos artísticos (Fig. 5).

Los modelos de difusión de los museos anteriormente mencionados se ven lastrados por una limitación adicional. La contextualización básica que proponen se reduce generalmente al ámbito artista-obra. Por ejemplo, aunque es posible consultar diferentes obras de un mismo artista y acceder a su biografía, o viceversa, no se proporcionan opciones para contraponer artistas de diferentes momentos o corrientes artísticas, obras de diferentes creadores o piezas artísticas de diferentes técnicas. Sólo es posible asociar una pintura con una fotografía si ambas pertenecen a la producción de un mismo artista. Esta tendencia podría entenderse como el resultado de "la centralización de la creación artística y de la teoría crítica del s. XX en el potencial creativo de individuos particulares" 15 . 


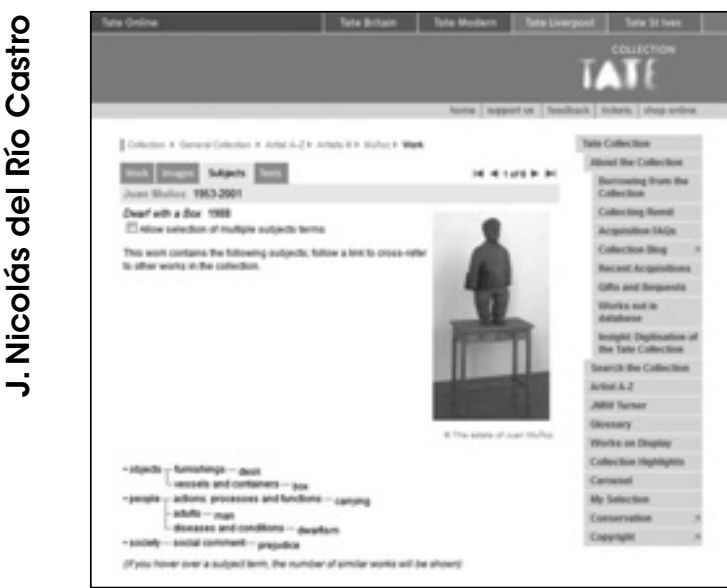

Fig. 6. Colección online de la Tate londinense. La catalogación de cada obra incluye un conjunto de términos descriptivos (esquina inferior izquierda) que funcionan como enlaces a otras piezas.

Los modelos de acceso a la colección mediante taxonomías - ya sea a partir de bases de datos o índices - presentan los fondos del museo como conjuntos de ítems aislados en compartimentos estancos. Este planteamiento organizativo hace que los museos que utilizan cualquiera de estos sistemas tiendan a funcionar como repositorios digitales para la consulta de datos puntuales, más que recursos destinados a proporcionar una experiencia de exploración y descubrimiento. La ausencia de valores relacionales amplios hace que la búsqueda de información quede resuelta - o no- en cada consulta y que la única alternativa de exploración consista en repetir el proceso: volver a la base de datos, a la selección inicial de obras, a la cronología o al índice y elegir una nueva opción. Como resultado, las visitas a los museos con este tipo de acceso son de carácter episódico ya que, una vez hecha la consulta, no hay necesidad de repetirlas para seguir indagando.

Los ejemplos más próximos a un verdadero contexto relacional son muy escasos entre los museos de arte contemporáneo analizados y tan sólo la Tate londinense y el Walker Art Center de Minneapolis ofrecen aproximaciones de diferente calado. El museo británico, además de

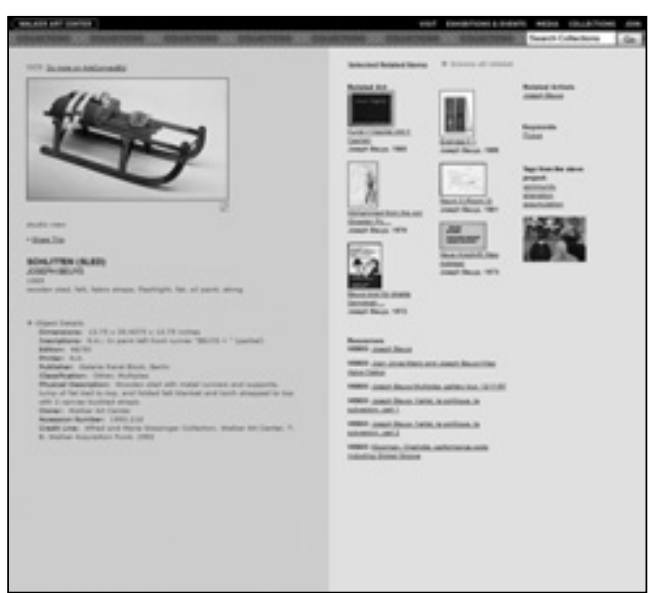

Fig. 7. Colección online del Walker Art Center de Minneapolis. A partir de una obra se ofrecen recursos relacionados: otras obras, otros artistas, palabras clave y otros materiales disponibles.

poner a disposición de sus visitantes índices de diversas categorías, propone descubrir obras transversalmente a partir de sus aspectos comunes. El museo asigna a cada pieza un grupo de etiquetas, tanto descriptivas como connotativas (Fig. 6) que funcionan como enlaces a otras obras con las que comparten uno o varios descriptores. De este modo, las obras que contienen los mismos términos permiten establecer un entramado de relaciones que funcionan como una vía de exploración alternativa para los visitantes cuyos intereses no encajan en los parámetros organizativos de la catalogación museográfica. Aún así, el tejido relacional que propone la Tate se limita a las obras; no se plantean relaciones entre creadores, corrientes artísticas, técnicas o contexto histórico-social. La propuesta del Walker Art Center estadounidense es más elaborada y se aproxima a una interrelación global de los recursos online del museo. Por ejemplo, al seleccionar una obra de Joseph Beuys, (Fig. 7) se muestra, no sólo la obra y su ficha técnica, sino también enlaces a cuatro tipos de contenidos asociados: obras relacionadas (del mismo autor), artistas relacionados, recursos relacionados (tanto en el centro de documentación como en la Red) y palabras 


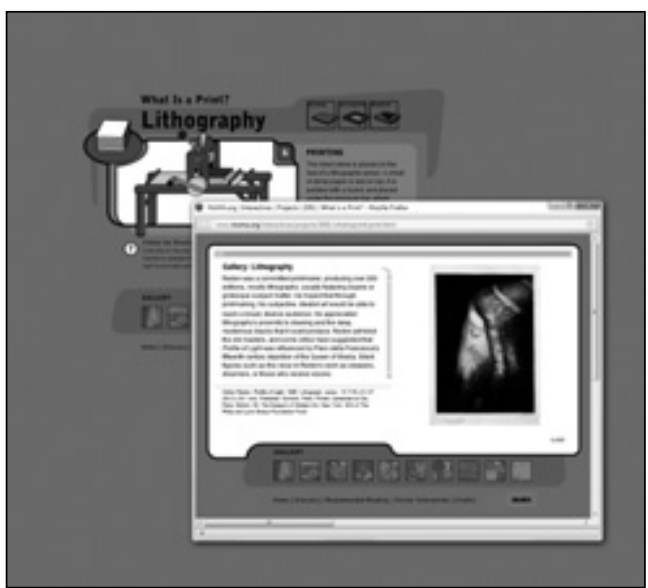

Fig. 8. MoMA de Nueva York. Interactivo "What is a print" (¿Qué es un grabado?).

clave, un planteamiento similar al de la Tate aunque menos exhaustivo. A diferencia de los primeros modelos que hemos descrito, los contextos relacionales desarrollados por ambos museos ofrecen al visitante opciones de consulta que invitan a repetir la visita para descubrir qué contenidos hay detrás de las conexiones que sugiere la colección.

Una segunda opción para difundir los fondos artísticos del museo en la Red son las exposiciones online. Éstas pueden ser el complemento a una exposición física, como la que dedica el MOMA de San Francisco a una obra de Louise Bourgeois, o pueden existir sólo en versión online, como la retrospectiva del MACM de Montreal sobre Claude Tousignant ${ }^{16}$. Este tipo de proyectos son más populares entre los grandes museos anglosajones; así lo delata el hecho de que la mayoría de museos fuera de este ámbito apenas llevan a cabo este tipo de producciones y cuando las elaboran no suelen ser más de dos. Sin embargo, el modelo más común entre los museos analizados no consiste realmente en exposiciones online sino en reseñas de exposiciones físicas. Cuando esto ocurre, la información online no da pie a que los futuros visitantes presenciales lleguen al museo

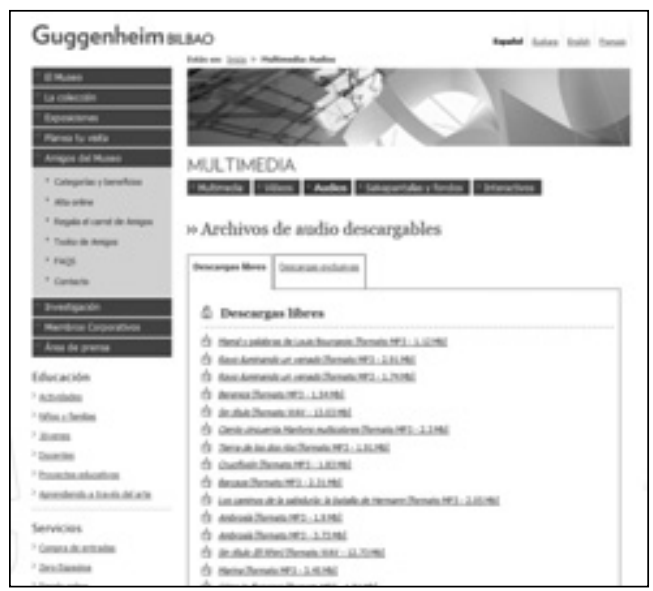

Fig. 9. Fondos documentales del Guggenheim de Bilbao. Los audios archivados en la sección "multimedia" se organizan en directorios sin vínculos a las obras.

mejor informados ni a que los visitantes que ya disfrutaron de la exposición revisen el material online a posteriori para profundizar o reflexionar. Como resultado, las exposiciones online concebidas únicamente con fines promocionales hacen que las webs de museos tiendan a percibirse como folletos digitales cuyo único objetivo consiste en redirigir a las visitas virtuales al museo físico. Al igual que ocurría con las colecciones online, un reducido número de museos (el ICA de Filadelfia, el museo Van Abbe de Eindhoven o el FRAC Center de Orleans, entre otros) proporcionan documentación adicional para algunas exposiciones físicas en forma de ficheros descargables: guías de la exposición, hojas de sala, textos de paneles o materiales didácticos. Pero, en realidad, estos contenidos no abren nuevos caminos de investigación sobre otras exposiciones, obras o artistas, sino que simplemente aprovechan la capacidad de la Red como biblioteca digital.

Los módulos interactivos pueden considerarse como una variante de las exposiciones online ${ }^{17}$. De hecho, el MOMA de Nueva York incluye ambos modelos dentro de su sección interactivos, cuyas más de 100 propuestas abarcan diferentes temáticas y aproximaciones: un 
interactivo sobre las diversas técnicas de grabado (Fig. 8), una retrospectiva sobre 40 años de escultura de Richard Serra o un promocional de una publicación sobre mujeres artistas ${ }^{18}$. Aunque no existe un modelo estándar y su complejidad varía enormemente ${ }^{19}$, los interactivos junto con las exposiciones más elaboradasson contenidos que se caracterizan por incluir una miscelánea de medios (audios, vídeos, galerías, textos, juegos, etc.), por demandar del usuario cierto grado de implicación y por funcionar como ensayos monográficos de reducido tamaño. A pesar de no tener un carácter marcadamente experto, no por ello son menos rigurosos y, tanto por su amplitud como por sus contenidos multimedia, sirven como una base atractiva y accesible para iniciar a las audiencias menos conocedoras.

\section{La difusión online de fondos documentales}

Entre los recursos documentales más extendidos se encuentran vídeos y audios (Les Abattoirs de Toulouse, CCCB de Barcelona), y junto a ellos aparecen, aunque con menor frecuencia, guías de exposiciones y folletos (Baltic Mill británico, MACRO de Argentina), materiales educativos (Fundación Montenmedio de Cádiz, MARCO de México), críticas y reseñas (MAC's belga, MAC de Val de Marme, Heide australiano) e incluso revistas (Kiasma de Helsinki, Tate). Esta riqueza sólo resulta significativa cuando se enlaza con las obras a las que hacen referencia pero sólo unos pocos de los museos analizados vinculan las obras a recursos complementarios. Con frecuencia los fondos documentales se presentan organizados en directorios según su formato o tipo de contenido (vídeos, materiales para docentes, dossiers, etc.) pero a ojos del visitante resultan una pluralidad de fragmentos dispersos ordenados por orden alfabético o simplemente alojados en una sección de la web. Por ejemplo, los audios y vídeos que ofrece el Guggenheim de Bilbao se encuentran reunidos en la sección multimedia (Fig. 9) pero sin vinculación a las obras a las que hacen referencia. El mismo patrón se repite con los módulos interactivos del MOMA de San Francisco y los materiales educativos de la South London Gallery, de la Schirn Kunsthalle de Frankfurt o del ACCA de Melbourne ${ }^{20}$.
Cuando el acceso a los fondos artísticos y documentales se plantea únicamente bajo criterios afines a la catalogación y documentación museográfica, queda al descubierto cierta desconexión con un amplio sector del público que se muestra menos preocupado por las clasificaciones de los profesionales del arte y más interesado en descubrir obras, artistas o tendencias. No se trata de que desaparezca la capacidad de repositorio de las webs de museos, puesto que cumple una función para determinados segmentos de público; se trata de que la información también resulte invitadora para un rango mayor de visitantes. Aunque la popularidad de los museos en la Red y el elevado crecimiento de su audiencia virtual han impulsado a los museos a ampliar y mejorar su oferta online, entre los museos de arte contemporáneo analizados son pocos los que han reconocido "la importancia de contextualizar sus colecciones, de centrarlas en el usuario, de la interactividad y de usar técnicas de gestión de la información que cumplan las necesidades de los usuarios" 21 .

En los ejemplos anteriores, todos ellos extraídos de museos de arte contemporáneo, hemos visto — con la excepción de la Tate y el Walker Art Center- como la contextualización ocurre a pequeña escala y como ésta se centra fundamentalmente entre obra y creador. Por contraste, otros museos online de diferente tipología proponen iniciativas que sirven como valiosos modelos de referencia para la difusión basada en relaciones de significado.

\section{La contextualización online: modelos institucionales}

Utilizaremos dos museos de diferente envergadura, el Art Institute de Chicago y el Metropolitan de Nueva York, para analizar la divulgación mediante modelos de contextualización extensa. El museo de Chicago complementa las categorías habituales de catalogación con una propuesta transversal a ellas. Se trata de ocho selecciones temáticas que facilitan la exploración conjunta de obras de diferente técnica, época, autoría y procedencia (Fig. 10222. Los ocho temas propuestos resultan un tanto aleatorios ya que proponen un acercamiento a la colección en base a parámetros heterogéneos: la zona geográfica en la que se ubica el museo 


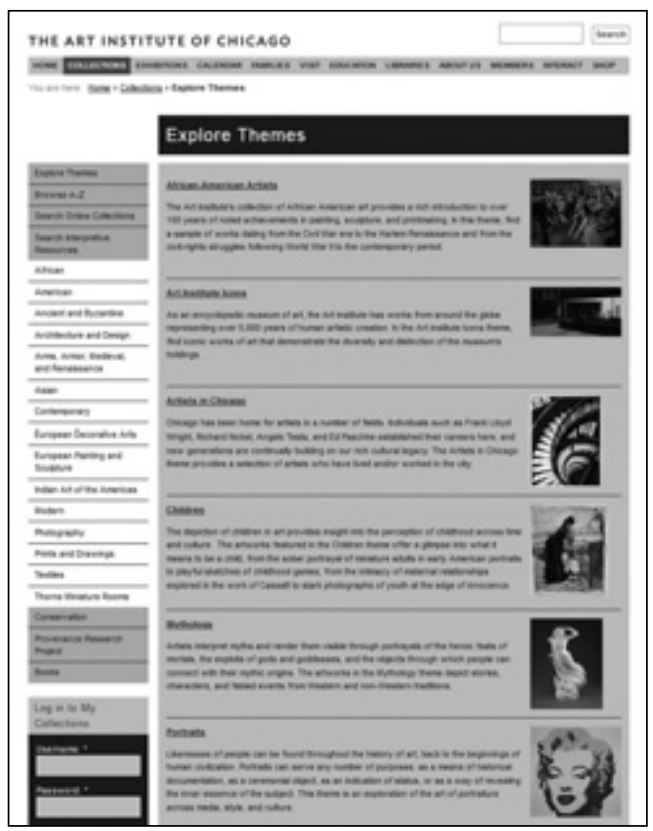

Fig. 10. Colección online del Art Institute of Chicago. Además de índices, es posible explorar la colección por temas.

(artistas de Chicago), las obras más representativas (iconos del Art Institute), tipos de obra (retrato) y temas diversos presumiblemente populares entre un público general (niños, mitología, etc.). Por ejemplo, la selección del lienzo de Edward Hopper "Noctámbulos", dentro de la categoría Iconos del Art Institute, muestra en primer lugar una imagen, un texto introductorio y una ficha técnica. Esta información sigue la pauta de los museos de arte contemporáneo que hemos descrito anteriormente, aunque se diferencia de ellos en que los datos sobre el artista y el departamento son enlaces $y$, por tanto, remiten a otros contenidos relacionados. Así, a partir del artista se accede a otras obras de la producción de Hopper y a partir del departamento, se pueden conocer otros fondos de arte norteamericano. En segundo lugar, también se indica si la obra se encuentra en exhibición y, en caso de ser así, se proporciona un enlace al conjunto de obras que se encuentran en la misma sala. En tercer lugar, se ofrece infor- mación sobre tres aspectos técnicos: un histórico de las exposiciones del museo de las que formó parte esta obra, una bibliografía en la que aparece reseñada la pieza, e información sobre su procedencia. En cuarto lugar y en contraste con los datos anteriores de carácter especializado, la sección consultas relacionadas propone exploraciones a través de rutas temáticas asociadas a la obra: pintura (1900-1955), moderno, Nueva York, arquitectura, figurativo, luces y sombras, etc. En quinto y último lugar, la sección recursos de interpretación ofrece al visitante herramientas para comprender y apreciar la obra; en este caso se trata de un fichero de audio correspondiente a una conferencia sobre Hopper. En resumen, la propuesta divulgativa del Art Institute combina tres aproximaciones: la exploración de temas afines, los datos técnicos sobre la obra y el uso de recursos de apoyo a la interpretación. A priori, este es un planteamiento de difusión que cubre las necesidades de un público con diferentes intereses y conocimientos sobre arte.

Otro ejemplo de una estructura contextual verdaderamente extensa corresponde al Timeline of Art History (Cronología de la Historia del Arte) desarrollada por el Metropolitan Museum de Nueva York. Se trata de una visión panorámica sobre arte mundial que sólo un museo de este calibre es capaz de abordar ya que ilustra todas las épocas artísticas gracias a su amplísima colección. Aunque resulte una propuesta inasumible para muchos museos, resulta revelador conocer su planteamiento. El museo define este recurso como "una referencia invaluable y una herramienta de investigación para estudiantes, educadores, investigadores y para cualquier persona interesada en el estudio del arte y temas afines" ${ }^{23}$. La relevancia de este texto es que identifica claramente como objetivo divulgativo a una audiencia amplia y diversa, lo que implica que los recursos online han sido concebidos y desarrollados para satisfacer intereses diferenciados.

Efectivamente, el visitante puede acceder a la información de varias formas: a través de una línea temporal, mapas geográficos, índices y temas. La página inicial está maquetada como la portada de un periódico con cuatro secciones principales (Fig. 11): una barra superior con diez 


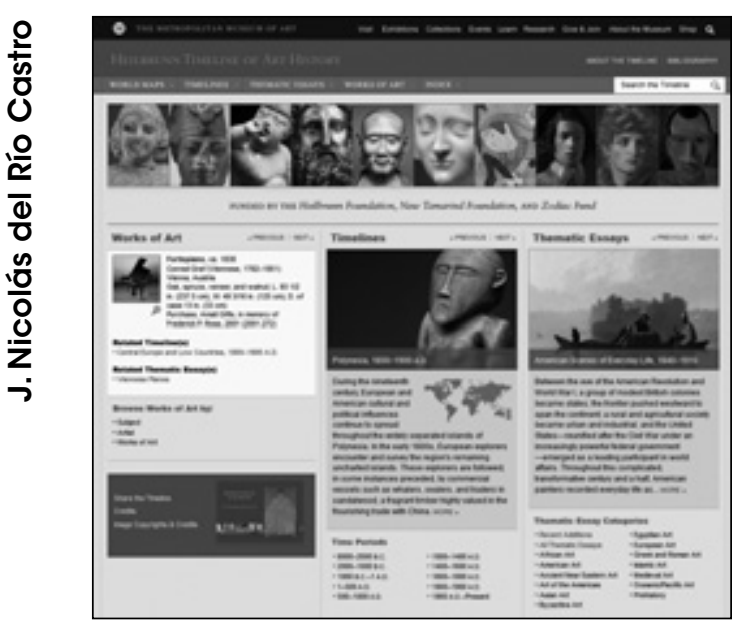

Fig. 11. Metropolitan Museum, The Timeline of Art History. Acceso a los fondos del museo a través de mapas, temas, ensayos, épocas e índices.

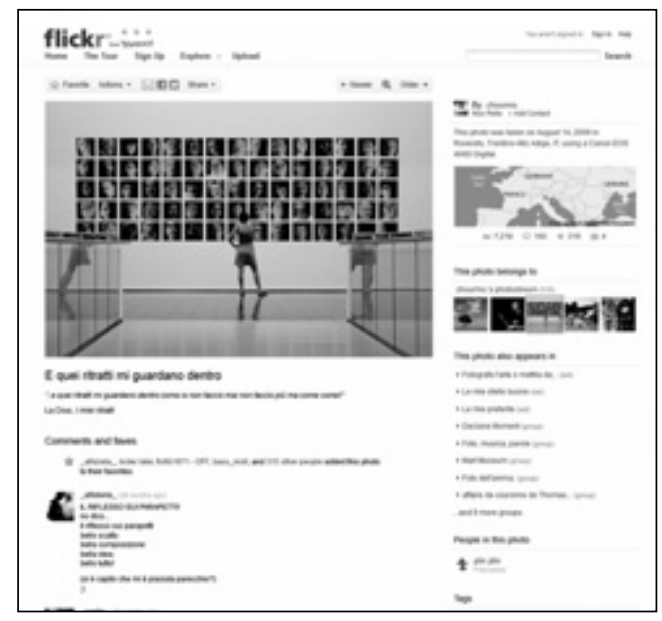

Fig. 12. Fotografía de una exposición del MART de Trento en la página de Flickr. Bajo la imagen se incluyen los comentarios de diversos usuarios. obras representativas de otros tantos periodos artísticos, desde la prehistoria hasta la actualidad, y un cuerpo central que contiene una obra destacada, un periodo artístico y un ensayo temático. La característica común a todos los bloques de contenido es que son aleatorios, es decir, cada vez que se consulta la página se muestran contenidos diferentes, elegidos al azar entre todos los contenidos disponibles. Presumiblemente, este modo de presentación está concebido para visitantes que exploran esta sección de la web sin una idea demasiado concreta o que se acercan de forma lúdica, dejándose guiar como punto de partida por las sugerencias, siempre cambiantes, que propone el museo. Una segunda opción de acceso consiste en la utilización de mapas y cronologías que ofrecen una aproximación de general a particular. Posiblemente esta opción está concebida para visitantes que tengan conocimientos o interés en una cultura o una época y quieran profundizar en ella. Una tercera posibilidad, presenta ensayos (por ejemplo, Influencias africanas en el arte moderno o Dualismo en el arte andino) que permite explorar los fondos del museo a partir de nodos temáticos. Finalmente, una cuarta opción proporciona índices alfabéticos para acceder directamente a información específica como número de catálogo, título de obra, etc.; podríamos asumir que esta modalidad es más relevante para investigadores.

El planteamiento online de ambos museos supone una reformulación interactiva de los fondos artísticos y documentales. En contraste con grandes cantidades de registros organizados en categorías y directorios, las propuestas de contextualización implican una selección previa. De este modo el museo puede establecer un entramado de asociaciones que sugieren alternativas y presentan nuevas relaciones al visitante. La forma de conectar la información puede darse a tres niveles: horizontal, enlazando temas afines; vertical, profundizando en un mismo tema y transversal, interrelacionando áreas y conceptos diversos. El Rijksmuseum de Ámsterdam, que también presenta parte de su colección online de forma contextualizada, ejemplifica este aspecto en su texto de presentación: "los enlaces permiten interconectar objetos de varios departamentos de la amplia colección del 


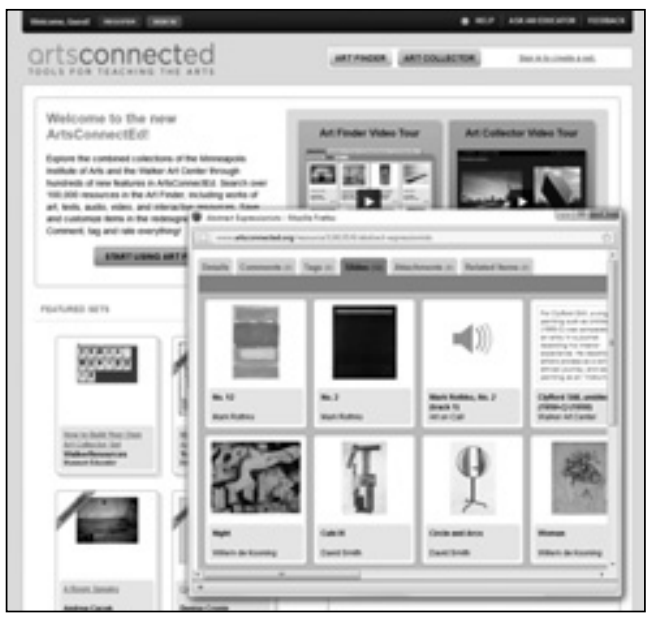

Fig. 13. Arts Connected (Walker Art Center de Minneapolis y Minneapolis Institute of Arts). Herramientas para reorganizar los fondos online del museo. En la imagen se muestran los contenidos de un dossier sobre expresionismo abstracto elaborado por un estudiante.

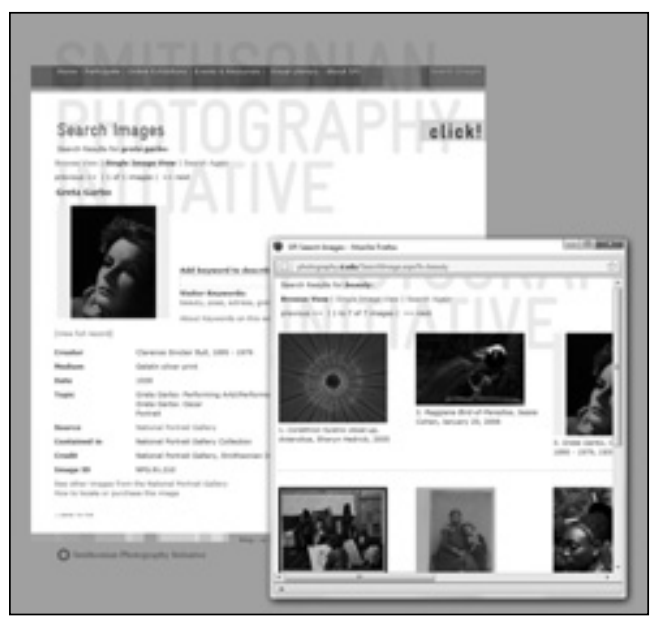

Fig. 14. Smithsonian Photography Initiative. El término "belleza", propuesto por la audiencia, enlaza con otros fondos descritos con la misma etiqueta. museo; unir una pintura con una jarra de plata, por ejemplo, o un paisaje del siglo XIX con su antecedente del XVII"24. Este esfuerzo da como resultado una base de conocimiento más significativa que la mera presentación de datos. La selección personal de información que realiza cualquier visitante — siempre dentro de los límites que permite la estructura relacional diseñada por el museo- resulta más conducente a una consulta que no se agota con una sola visita y, sobre todo, resulta más valiosa y satisfactoria a nivel personal.

Los ejemplos citados muestran casos de contextualización desarrollados por los museos, sin embargo, la Web $2.0^{25}$ ha aportado formatos basados en la participación de los usuarios (foros, blogs, wikis, redes sociales...) que abren las puertas a la posibilidad de que los visitantes reorganicen y reestructuren los fondos online del museo desde su propia perspectiva.

\section{La contextualización online: modelos con aportaciones de la audiencia}

La Web social ha permitido que los visitantes de museos online encuentren espacios para participar, tanto en el website de la institución como en webs externas que funcionan como satélites promocionales del museo. Por ejemplo, de forma interna, la colección online del MCA de Denver y la exposición online sobre Olafur Eliasson del MOMA de San Francisco permiten escribir apreciaciones personales (de forma similar a un libro de visitas) aunque sin una interacción colectiva entre los que contribuyen. Los museos que disponen de blogs (Centro José Guerrero de Granada, MassMOCA de Massachusetts) sí permiten una comunicación directa con el museo y las réplicas de otros participantes. De forma externa, la presencia de museos en comunidades de vídeo como YouTube (MUMOK de Viena, ARKEN de Dinamarca) o de fotografía, como Flickr (MART de Trento o Stedelijk de Amsterdam) también permiten a los usuarios escribir comentarios, pudiendo llegar a generar cierto debate entre los participantes (Fig. 12). Cada vez más, los museos también están presentes en redes sociales de gran popularidad como Facebook o Twitter (Les Abattoirs de Toulousse, MOCA de Los Ángeles), cuya actividad gira en torno a 
grupos de interés, intercambio de información y recomendaciones personales.

Gracias a su carácter participativo, la Web 2.0 ha puesto en valor los conceptos de aportación personal y contribución colectiva. Algunos museos han entendido esta posibilidad como una acción paralela a la web del museo, proporcionando espacios separados (blogs, foros ${ }^{26}$ y webs de redes sociales) en los que el público puede expresarse sin interferir con la oferta oficial de la entidad. Otros museos, de forma más innovadora, proporcionan herramientas para que parte de sus recursos online puedan ser manipulados -e incluso creados - por los visitantes. Por ejemplo, el Patio Herreriano enfoca esta funcionalidad como un componente lúdico para los más jóvenes, que tienen la posibilidad de hacer sus propios álbumes (grupos de imágenes de la colección) y constelaciones (imágenes agrupadas bajo un tema común) ${ }^{27}$. La Tate plantea la selección personal de obras en relación con la ubicación de éstas en el museo físico, de manera que las obras seleccionadas en la Red se convierten en un itinerario que es posible imprimir como guía para la visita presencial ${ }^{28}$. El Walker Art Center ${ }^{29}$ es el único museo de arte contemporáneo que permite combinar obras de la colección con recursos adicionales de vídeo, texto y audio de tal forma que el resultado final son dossiers multimedia creados por los visitantes (Fig. 13). El MoMA de Nueva York, en vez de invitar a la audiencia a reutilizar sus fondos online, propone a los visitantes que los utilicen como inspiración para crear sus propios podcasts (audioguías) ${ }^{30}$ que, si son aprobados por el museo, pasarán a formar parte de la lista oficial. De forma similar, el Guggenheim de Bilbao propone a los profesores crear unidades didácticas e incorporarlas a su repositorio educativo WikiDocentes ${ }^{31}$. La posibilidad de aportar fotografías o vídeos personales es más compleja debido a las limitaciones que imponen los derechos de reproducción, aún así, el MART de Trento o el Stedelijk de Ámsterdam ${ }^{32}$ proponen al público enviar sus fotografías de las actividades o del edificio y de este modo documentar las miradas particulares de los visitantes sobre el museo. Individualmente, la reorganización personal de los recursos online, la aportación de materiales propios y las recomendaciones personales suponen una contextualización basada en las prefe- rencias particulares de cada visitante. En conjunto, se convierten en múltiples puertas de entrada a los fondos del museo para que otros visitantes con intereses similares puedan utilizarlas como puntos de acceso.

Una forma adicional de incorporar no sólo una contextualización personal, sino también el propio lenguaje del visitante es el etiquetado social (social tagging o folksonomies), que consiste en que los visitantes describan con sus propias palabras las obras de la colección. Aunque mencionamos anteriormente cómo la Tate utilizaba términos descriptivos para su colección, éstos eran asignados por el museo, no por el público. En el ejemplo del Smithsonian (Fig. 14) se aprecia cómo, paralelamente a los términos técnicos de catalogación, los visitantes describen una fotografía en blanco y negro de Greta Garbo con otros términos más prosaicos y emotivos como belleza, pose, soledad o Hollywood ${ }^{33}$. Una experiencia similar se había llevado a cabo a finales de 2005 en el Metropolitan de Nueva York; un grupo de voluntarios había añadido términos descriptivos a 30 imágenes de piezas artísticas. Al comparar los resultados con el catálogo de la institución se comprobó que más del $80 \%$ no coincidían. Ante este dato, el museo reconocía que había "un abismo semántico enorme entre los museos y el público" ${ }^{34}$. El etiquetado social puede ayudar a aproximar ambos discursos. Este formato 2.0 acerca la colección al visitante gracias una contextualización temática realizada en un lenguaje que oscila entre lo obvio y lo mundano pero que resulta más próximo para una gran parte de los visitantes, a quienes puede servir como guía de consulta. Al clasificar los fondos del museo con términos no científicos, algunos museos creen que el etiquetado social puede afectar negativamente a la fiabilidad de la información institucional. Por el contrario, otras instituciones ven la oportunidad de atraer a un público que hasta ahora les había considerado con reticencia. En último término, la convivencia de dos lenguajes diferentes en la web institucional encubre cierto equilibrio de poder entre museo y público que aún resulta difícil de calibrar.

La Red ofrece múltiples opciones para que los museos presenten sus fondos artísticos y documentales de forma significativa para audiencias 
con diferentes intereses y niveles de conocimiento. Sin embargo, la escasez de planteamientos basados en relaciones de significado entre los 40 museos analizados sugiere que la mayoría de las instituciones sigue apegada a modelos de difusión deudores de una catalogación tradicional desarrollada por profesionales para públicos expertos. Como posible alternativa a una oferta online centrada principalmente en la "provisión de información" Anderson propone un "modelo de aprendizaje" ${ }^{35}$. Éste no debe entenderse desde la perspectiva académica de la educación formal, sino como una propuesta informal en la que los museos online proporcionan contenidos que favorecen un aprendizaje autodirigido. Si el acceso a los fondos está basado en un tejido relacional que facilita la consulta de intereses particulares y si, además, contempla la posibilidad de que los visitantes organicen los fondos online según sus gustos y necesidades, el museo estará invitando a sus visitantes a saber más y, adicionalmente, potenciará visitas repetidas para descubrir lo que no se pudo abarcar en una sola consulta.

Museos consultados

\begin{tabular}{|c|c|c|}
\hline$A C C A$ & Melbourne, Australia & accaonline.org \\
\hline ARKEN & Ishøj, Dinamarca & arken.dk \\
\hline ARTIUM & Vitoria-Gasteiz, España & artium.org \\
\hline Albright-Knox & Búfalo, EE.UU. & albrightknox.org \\
\hline Baltic Mill & Gateshead, Inglaterra & balticmill.com \\
\hline CCCB & Barcelona, España & cccb.org \\
\hline Centre Pompidou & París, Francia & centrepompidou.fr \\
\hline FRAC Center & Orleans, Francia & frac-centre.fr \\
\hline Fund. Montenmedio & Cádiz, España & fundacionnmac.com \\
\hline Heide & Heide, Australia & heide.com.au \\
\hline Hirshhorn & Washington, EE.UU. & hirshhorn.si.edu \\
\hline ICA Boston & Boston, EE.UU. & icaboston.org \\
\hline ICA Filadelfia & Filadelfia, EE.UU. & icaphila.org \\
\hline IMMA & Dublín, Irlanda & imma.ie \\
\hline José Guerrero & Granada, España & centroguerrero.org \\
\hline Kiasma & Helsinki, Finlandia & kiasma.fi \\
\hline Kunstmuseum & Wolfsburg, Alemania & kunstmuseum-wolfsburg.de \\
\hline Les Abattoirs & Toulouse, Francia & lesabattoirs.org \\
\hline MACM & Montreal, Canadá & macm.org \\
\hline MAC & Val de Marme, Francia & macval.fr \\
\hline MAC's & Grand Hornu, Bélgica & mac-s.be \\
\hline MACRO & Rosario, Argentina & macromuseo.org.ar \\
\hline MARCO & Monterrey, México & marco.org.mx \\
\hline MART & Rovereto, Italia & mart.tn.it \\
\hline MassMOCA & Massachusetts, EE.UU. & massmoca.org \\
\hline MCA & Denver, EE.UU. & mcadenver.org \\
\hline
\end{tabular}


Los fondos artísticos y documentales en los museos online de arte contemporáneo ...

\begin{tabular}{|lll|}
\hline MOCA & Los Ángeles, EE.UU. & moca.org \\
\hline MoMA & San Francisco, EE.UU. & sfmoma.org \\
\hline MoMA & Nueva York, EE.UU. & moma.org \\
\hline MUDAM & Luxemburgo & mudam.lu \\
\hline MUMOK & Viena, Austria & mumok.at \\
\hline Patio Herreriano & Valladolid, España & museopatioherreriano.org \\
\hline Reina Sofía & Madrid, España & museoreinasofia.es \\
\hline Schirn Kunsthalle & Frankfurt, Alemania & chirn.de \\
\hline South London Gallery & Londres, Inglaterra & southlondongallery.org \\
\hline Stedelijk & Ámsterdam, Holanda & stedelijk.nl \\
\hline Tate & Londres, Inglaterra & tate.org.uk \\
\hline Van Abbemuseum & Eindhoven, Holanda & vanabbemuseum.nl \\
\hline Walker Art Center & Minneapolis, EE.UU. & walkerart.org \\
\hline Whitney & Nueva York, EE.UU. & whitney.org \\
\hline Art Institute & Chicago, EE.UU. & artic.edu/aic \\
\hline Metropolitan & Nueva York, EE.UU. & metmuseum.org \\
\hline Rijksmuseum & Ámsterdam, Holanda & rijksmuseum.nl \\
\hline Smithsonian & Washington, EE.UU. & photography.si.edu \\
\hline
\end{tabular}

\section{NOTAS}

1 J. Bedno y E. Bedno, "Museum Exhibitions: Past Imperfect, Future Tense", 1999. [Fecha de consulta 11/07/2010]. http://www.aam-us.org/ pubs/mn/MN_SO99_Museum Exhibitions.cfm

${ }^{2}$ La presencia generalizada de los museos en la Red comenzó a partir de 1994 aunque algunos museos habían desarrollado experiencias puntuales en años anteriores. Véase, por ejemplo, $\mathrm{M}$. Kalfatovic, Creating a Winning Online Exhibition: a guide for libraries, archives, and museums, American Library Association, Chicago, 2002, p. xv.

3 Algunas instituciones temían que las versiones online de los museos llegasen a ser una amenaza para la supervivencia del museo físico, otras consideraban que el uso de Internet era un mero recurso publicitario sin valor añadido y otras miraban con recelo a una opción de difusión con un componente tecnológico. No obstante, otros museos estaban dispuestos a probar suerte en la Red y buscaban resolver cuestiones de índole práctica en un campo nuevo sin referencias contrastadas.

${ }^{4}$ En la actualidad se ha superado la dicotomía museo real/museo virtual, que concebía dos espacios separados, incluso rivales. El término "museo online" elimina este antagonismo y entiende el museo en la Red como una prolongación y un complemento del museo físico.

${ }^{5} \mathrm{~T}$. L. Teather y K. Wilhelm, "Web Musing: Evaluating Museums on the Web from Learning Theory to Methodology", en Museums And The Web, Nueva Orleans, 11-14 de marzo, 1999. [Fecha de consulta 09/07/2010] http://www.archimuse.com/mw99/pa pers/teather/teather.htm

${ }^{6}$ En la Red el usuario no está obligado a una lectura secuencial sino que puede acceder a los contenidos de forma no-lineal; para ello, sólo es preciso que estén interconectados mediante vínculos.

${ }^{7}$ C. Beardon y S. Worden (1997). "The Virtual Curator: Multimedia Technologies and The Roles of Museums", en E. Barret y M Redmond (1997). Contextual Media: Multimedia and Interpretation. Cambridge, MA: MIT Press. p. 75.

8 S. Kenderdine, "Inside the Meta-center: a Cabinet of Wonder", s/f. [Fecha de consulta 12/07/2010] http://archive.amol.org.au/about_amol /part1.asp

$9 \mathrm{H}$. Dreyfus, On the Internet, Routledge, Nueva York y Londres, 2009, p.11. 
10 G. Hoptman, "The Virtual Museum and Related Epistemological Concerns" en E. Barret, Sociomedia: Multimedia, Hypermedia, and the Social Construction of Knowledge. MIT Press, Cambridge, Massachusetts, 1992, p. 141.

${ }^{11}$ B. Davis y J. Trant, Introduction to Multimedia in Museums: A Report by the International Council of Museums Committee on Documentation. ICOM-CIDOC Multimedia Working Group, La Haya, 1996, p. 6.

${ }^{12}$ B. J. Soren, "Research on 'Quality' in Online Experiences for Museum Users" [Fecha de consulta 12/07/ 2010] http://www.chin.gc.ca/English/ Pdf/Digital_Content/Research_Quality/research_quality.pdf

${ }^{13}$ S. Bautista, "La virtualidad a las puertas del s. XXI" en Museología: un campo del conocimiento. Museología e historia. Córdoba, Argentina, 5-11 de octubre, 2006, p. 137. [Fecha de consulta 4/07/2010]http://www.Irzmuenchen.de/ iims/icofom/ iss_35.pdf

14 NavigArt utiliza más de 50 criterios para la documentación de obras aunque en su versión online se reduce a diez opciones. Véase "7 réponses a 7 questions en guise d'introduction à Videomuseum". [Fecha de consulta 18/07/2010] http://www.videomuseum.fr/IMG/pdf/ Videomuseum-Plaquette-francais2.pdf

${ }^{15} \mathrm{~J}$. Trant, "Understanding Searches of an On-line Contemporary Art Museum Catalogue" en Archives \& Museum Informatics, Albuquerque, New Mexico, 22-25 de marzo, 2006. [Fecha de consulta 06/07/2010] http://conference.archimuse.com/files/ trantSearchTermAnalysis061220a.pdf

16 http://www.sfmoma.org/multi media/interactive_features/41

http:// tousignant.virtuel.macm.org

${ }^{17}$ Los museos ya habían explora- do con notable éxito el formato interactivo en CD-Roms comerciales y posteriormente en DVD. Véase, por ejemplo, una reseña del periódico El País sobre la colección del Museo Thyssen-Bornemisza en CD-Rom: "El Museo Thyssen se abre a los visitantes virtuales" en El País, 21 de marzo de 1997.

${ }^{18} \mathrm{http}: / /$ www.moma.org/explore/ multimedia

http://www.moma.org/interactives/pro jects/2001/whatisaprint/flash.html http://www.moma.org/interactives/ex hibitions/2007/serra/

http://www.moma.org/explore/publica tions/modern_women

${ }^{19}$ Por ejemplo, la exposición online de ARTIUM ¿Qué pasa, Chati? contiene únicamente un texto curatorial y una selección de imágenes, mientras que la exposición del MoMA de San Francisco Anselm Kiefer, Heaven and Earth contiene vídeos, audios y secciones que documentan los ejes temáticos de su obra.

${ }^{20} \mathrm{http} / / / w w w . g u g g e n h e i m-b i l b a o$ .es/secciones/multimedia/audios.php?i dioma=es

http://www.schirn-kunsthalle.de/ index.php?do=connected_download \&lang=en

http://www.accaonline.org.au/Educati onKits

http://www.southlondongallery.org/ page/3100/Teachers+Packs

21 T. J. Baillargeon, "Planning, Developping and Evaluating eMuseums; Step-by-step Handbook for Museum Professionals", 2008, p. 1. [Fecha de consulta 18/07/2010] http:// krex.k-state.edu/dspace/handle/2097 1699

${ }^{22}$ http://www.artic.edu/aic/collec tions/citi/themes

$23 \mathrm{http}: / / w w w . m e t m u s e u m . o r g /$ TOAH/intro/atr/atr.htm

24 http://www.rijksmuseum.nl/ collectie/ontdekdecollectie
${ }^{25}$ Este término, acuñado por Tim O'Reilly en 2005, describe formatos online que se caracterizan por las aportaciones de particulares y la creación colectiva. Algunos ejemplos populares son Wikipedia (una enciclopedia realizada por los usuarios), Flickr (una web para compartir imágenes fotográficas), Facebook (una comunidad social) o los blogs.

${ }^{26}$ Los foros, uno de los modelos 2.0 inicialmente adoptados por los museos, desaparecieron paulatinamente de las webs de museos de arte contemporáneo entre 2007 y 2009. Sólo el Guggenheim de Nueva York mantiene el suyo; el del Patio Herreriano aunque permanece accesible, no incorpora aportaciones desde 2008.

${ }^{27} \mathrm{http}: / /$ www.exploradorarte. com /ArTempus/

${ }^{28} \mathrm{http}: / /$ www.tate.org.uk/ modern /explore/

${ }^{29}$ En colaboración con el Minneapolis Institute of Art: http://www. artsconnected.org/

${ }^{30}$ La apertura a contribuciones externas surgió a raíz de que el colectivo Art Mobs crease versiones alternativas a los "podcasts" (término derivado de iPod, el nombre comercial de un popular reproductor de música) oficiales del MoMA.

[Fecha de consulta 05/07/2010] http://www.MoMA.org/visit_MoMA/ createyourown.html

31 http://www.guggenheim-bilbao .es/wikidocentes/

32 http://journal.stedelijk.nl/2011/ 04/fotos-stedelijk-museum

${ }^{33}$ http://photography.si.edu/Search Image. $a$ sp $x$ ? $t=3 \& q=$ garbo\&id $=800 \&$ in dex $=1$

34 J. Trant, op. cit.

35 M. Anderson, "A Common Wealth: Museums in the Learning Age" [Fecha de consulta 06/07/2010] http://www.culture.gov.uk/images/ publications/Common_Wealth2.pdf 